Chapter 6

\title{
New Treatment Modalities for Ocular Complications of Endocarditis
}

\section{Ozlem Sahin}

Additional information is available at the end of the chapter

http://dx.doi.org/10.5772/56537

\section{Introduction}

Endophthalmitis is one of the most devastating diagnoses in ophthalmology. It is a serious intraocular inflammatory disorder affecting the vitreous cavity that can result from exogenous or endogenous spread of infecting organisms into the eye. [1] Endogenous endophthalmitis is less common and occurs secondary to hematogenous dissemination from a distant infective source in the body. Predisposing risk factors in patients with endogenous endophthalmitis usually exist, and they are correlated with the pathogenesis of the disease.[1] The risk factors are considered as infectious foci in the other parts of the body, intravenous drug abuse, diabetes mellitus, immunosuppressive therapy, intravenous hyperalimentation, fever of unknown origin, malignancies and male sex. [2-6] In most cases, independent of its origin, the presentation of endophthalmitis consists of reduced or blurred vision, red eye, pain, and lid swelling. [7] Progressive vitritis (Fig.1) is one of the key findings in any form of endophthalmitis, and in nearly $75 \%$ of patients have hypopyon (Fig. 2) which can be seen at the time of presentation. [7] Progression of the disease may lead to panophthalmitis, (Fig. 3) corneal infiltration, (Fig. 4) globe perforation and phthisis bulbi.(Fig. 5) [1,7] Endogenous endophthalmitis is a rare complication of infective endocarditis, and has been decreasing due to the availability of effective antibiotics. [8] To optimize visual outcome, early diagnosis and treatment are essential.[7,8] Over recent decades, advances in hygienic standards, improved microbiologic and surgical techniques, development of powerful antimicrobial drugs, and the introduction of intravitreal antibiotic therapy have led to a decreased incidence and improved management of endophthalmitis. [1,7] However, endophthalmitis still represents a serious clinical problem. This chapter focuses mainly on current principles and techniques for treatment of endophthalmitis. In addition, it addresses recent developments regarding anti-inflammatory and antimicrobial treatments. 


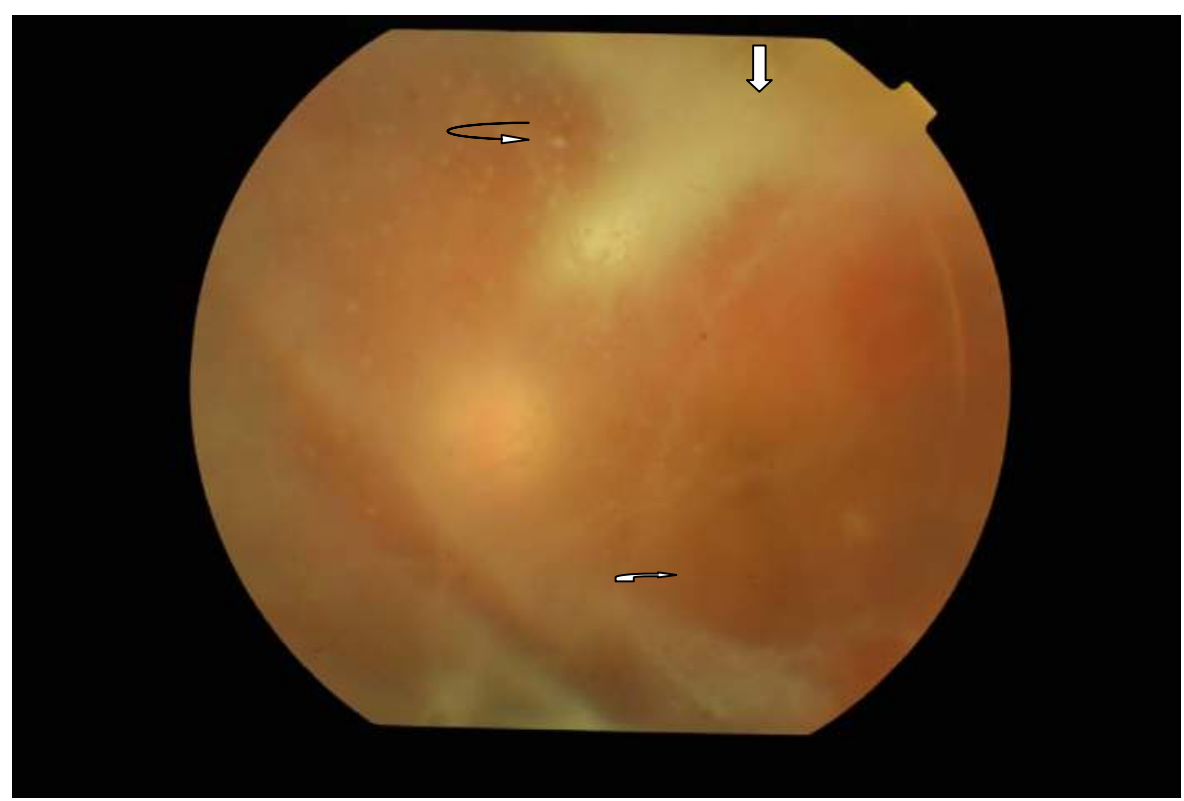

Figure 1. Note the dense vitritis, vitreous bands, $(\Longleftrightarrow)$ precipitates, $(\Longleftrightarrow$ ) and retinitis foci $(\bigcap)$ located superiorly.

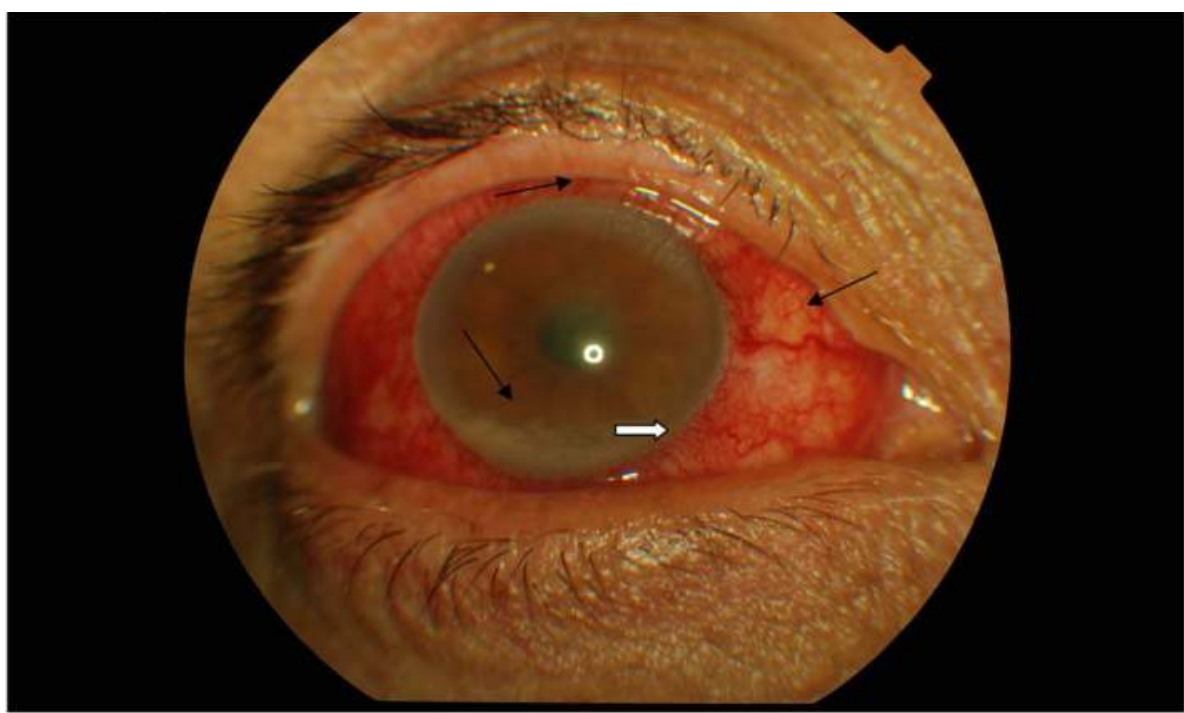

Figure 2. Note the 2-mm hypopyon $(\longrightarrow$ ) in the anterior chamber associated with diffuse ciliary injection $(\longrightarrow)$ 


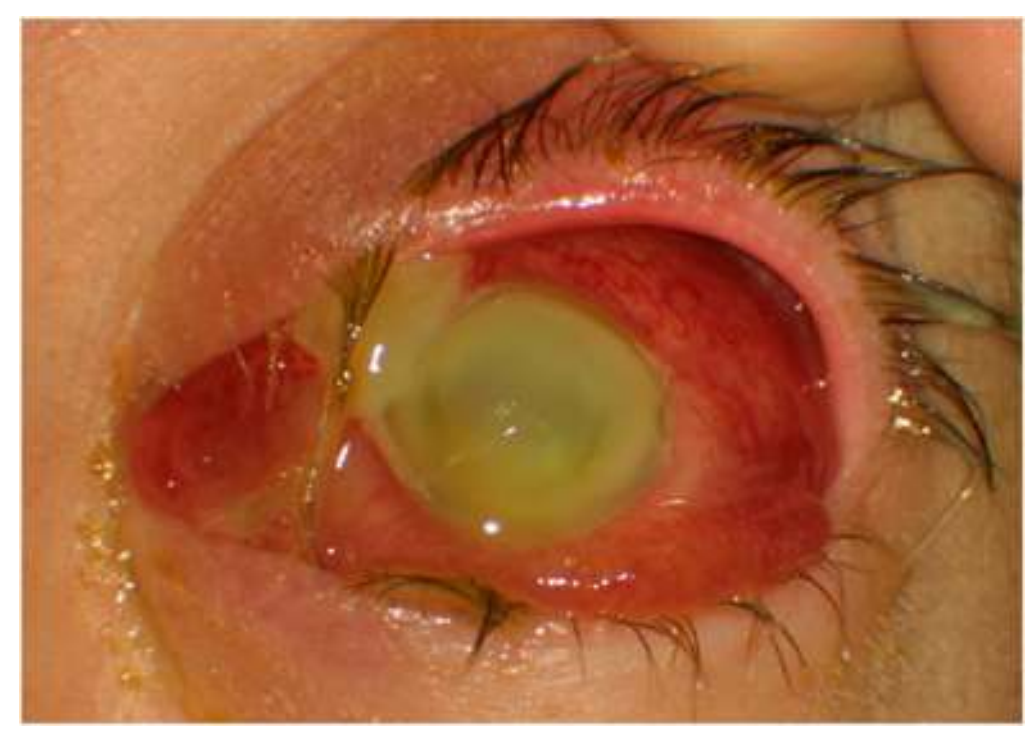

Figure 3. Note severe panophthalmitis with superonasal scleral abscess, and extrusion of pus from the limbus. (A Shwe-Tin, T Ung, C Madhavan and T Yasen: A case of endogenous Clostridium perfringens endophthalmitis in an intravenous drug abuser. Eye (2007) 21, 1427-1428; doi:10.1038/sj.eye.6702934; published online 3 August 2007)

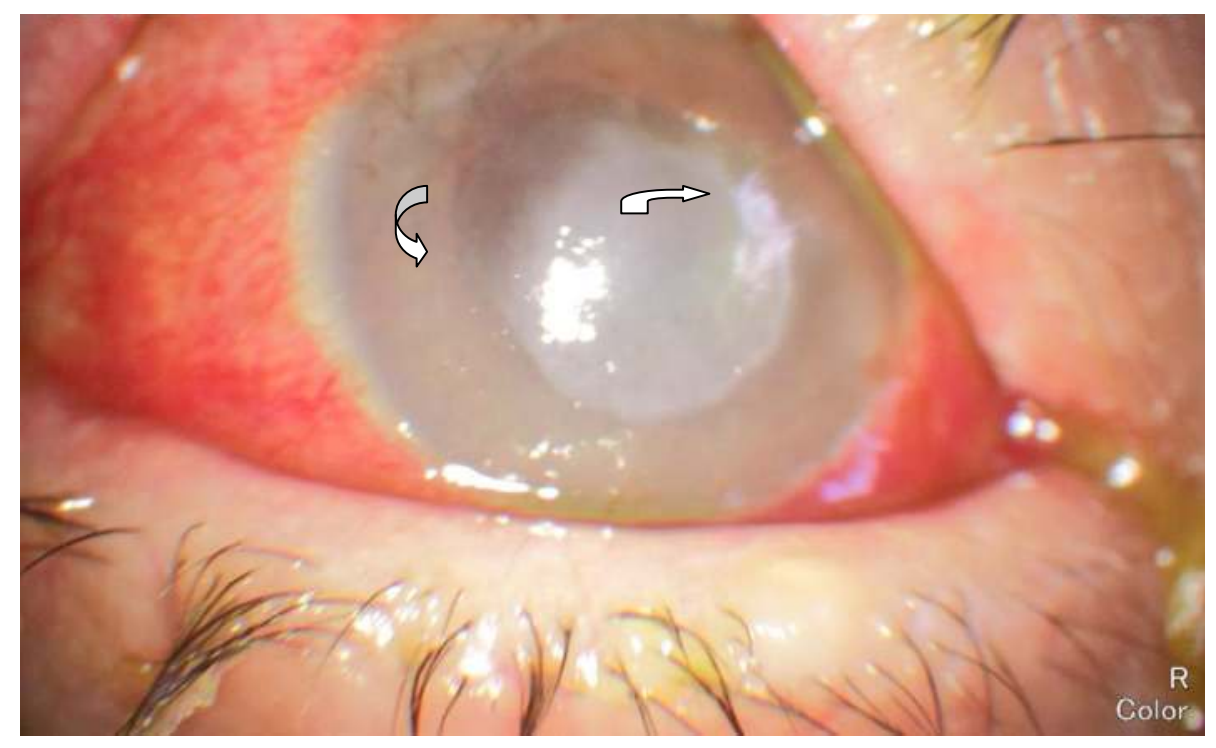

Figure 4. Note the central corneal infiltration $(\vec{S})$ and diffuse stromal edema $(\vec{S})$ 


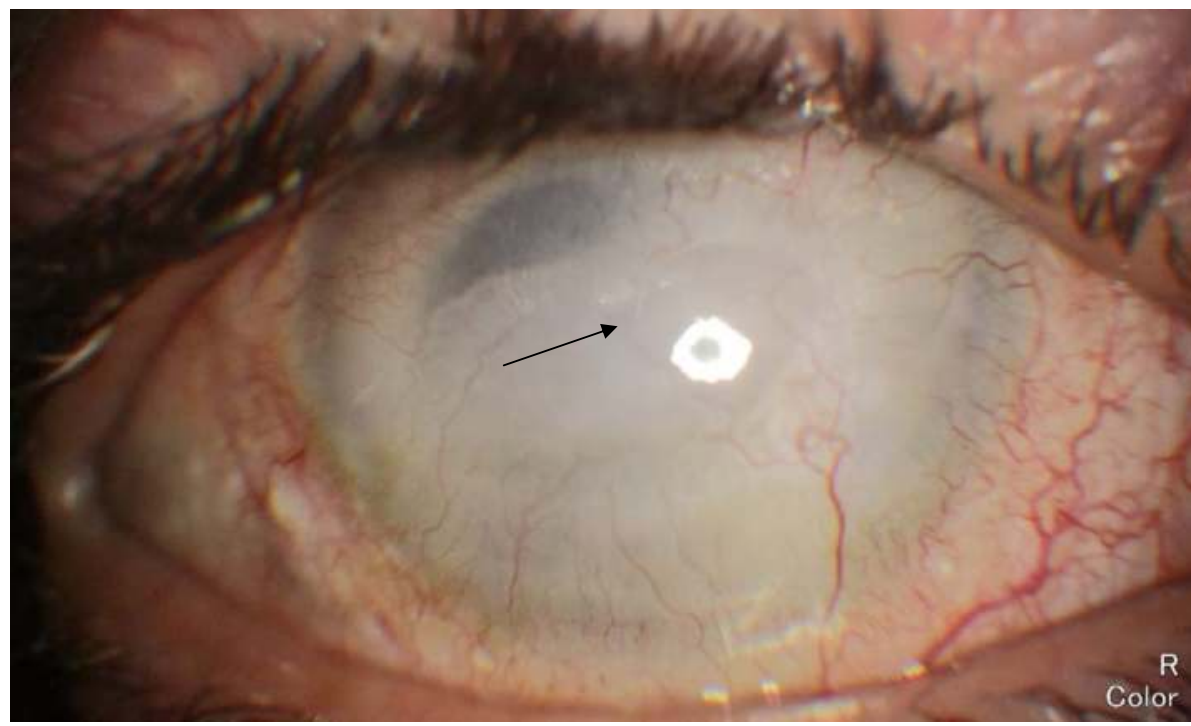

Figure 5. Note the phytisis bulbi associated with diffuse corneal vascularization and opacification (

\section{Pathogenesis}

In general, inflammation is a physiological response to invading pathogens or antigens which involve the migration of specific types of inflammatory cells out of the bloodstream into theaffected tissues. $[9,10]$ These cells release inflammatory agents such as cytokines, chemokines and other inflammatory markers to boost immune responses to kill the invading bacteria, viruses, and parasites or any other antigen. $[9,10]$ The linking of the antibody to the antigens forms an immune complex which is removed quickly by phagocytic macrophages; however owing to excessive antigen exposure or compromised immune response, the pathogens or their toxins are lodged into tissues and cause severe inflammation. [11,12] Excessive inflammatory response can damage the healthy tissues during this process. In excessive inflammation, the affected parts of the eye (the eyelids, sclera, iris, uvea, retina, optic nerve etc) become tender and inflamed. [11,12] Chronic or sever ocular inflammation can damage the delicate tissues and blood vessels in and around the eye resulting in vision loss. [13] Ocular inflammatory diseases occurs throughout the world independent of gender, race, ethnicity, or age and can be caused due to various factors such as infection, auto-immunity, trauma, drugs, or malignancy. [13] As the infectious pathogens enter the eye via hematogenous spread bacterial endotoxins, cytokins and growth factors induce the cellular mechanisms of reactive oxygen species (ROS) formation. [14] The key mediators are hydrogen peroxide $\left(\mathrm{H}_{2} \mathrm{O}_{2}\right)$, superoxide anions and peroxinitrite (NOO-), collectively termed as ROS. [14-16] ROS are believed to underlie many of the oxidative changes in various pathological conditions, and are known to 
enhance various mediators including increased expression of aldose reductase (AR), activation of protein kinase $C$ and redox-sensitive nuclear transcription factors such as NF- $\kappa B$ and activator protein-1 (AP-1). [15-17] ROS in turn lead to the cell membrane lipid peroxidation and formation of lipid aldehydes, e.g. 4-hydroxynonenal-(HNE) which conjugates with glutathione. (GS-HNE) Aldose reductase then catalyzes reduction of GS-HNE into glutathione 1,4 dihydroxynonene (GS-DHN) which acts as a transducer of inflammatory signaling by activating protein kinases system.[18,19] Eventually, the redox-sensitive transcription factors including NF- $\mathrm{kB}$ and AP-1 are activated in the nucleus, and transcribe many inflammatory genes that contribute to intraocular inflammation such as endophthalmitis. [19-21] Many inflammatory mediators, such as TNF- $\alpha$, IL-1 $\beta$, IL-6, and inducible-nitric oxide synthase (iNOS) require NF- $\kappa \mathrm{B}$ activation for their expression as their genes possess NF- $\kappa \mathrm{B}$ binding sequences in promoter regions. [19-21] Since the discovery of NF- $\kappa B$, a number of paradigms for its function have been established including its key role in the inflammatory and immune responses. NF- $\kappa \mathrm{B}$ stimulates immune cell function and acts in a pro-inflammatory manner by inducing the expression of cytokines, chemokines and their receptors. [19-21]These aspects of $\mathrm{NF}-\kappa \mathrm{B}$ function are undoubtedly central to the understanding of the overall action of this family of transcription factors, and they provide a foundation for therapeutic intervention in inflammatory diseases based on NF- $\kappa$ B inhibition. [22,23] AR mediates the activation of NF$\kappa B$ during oxidative stress caused by various stimuli and that inhibition of $A R$ attenuates the activation of key signaling kinases leading to deactivation of NF- $\kappa$ B. It is plausible that AR inhibitors could be potential therapeutic agents to treat the oxidative stress-induced ocular inflammation. [22,23] Alternatively, it has been shown that inhibition of AR prevents NF- $\kappa B$ activation in both cellular as well as animal models of ocular inflammation, thereby regulating the synthesis and secretion of pro-inflammatory markers suggesting that inhibition of AR by gene silencing or pharmacological agents could be an important strategy to treat ocular inflammatory diseases. [24,25] The evidence showing that lipid peroxidation products are being the excellent substrates of AR has led to this enzyme linked to inflammation and autoimmune mediated oxidative stress, besides diabetic complications. [26,27] Many studies with cell-culture and animal models of ocular inflammation have shown that inhibition of AR could ameliorate the inflammation induced by various stimuli including bacterial endotoxin, lipopolysachharide (LPS), high glucose, and cytokines. [24-27]The increased expression of AR in human cornea, lens, retina, and optic nerve has been shown during oxidative stress. [28,29] More recent reports suggest an unanticipated link between AR and ocular inflammation, e.g. inhibition of AR by pharmacological agents or by mRNA ablation leads to the prevention of high glucose-, TNF- $\alpha$-, and LPS-induced oxidative stress in human lens epithelial cells (HLEC) suggesting that AR could be another molecular target for the treatment of oxidative stressinduced ocular inflammation. [27] Although the eye is an immunologically privileged organ, it can also get damaged from the excessive immune response of the body when blood ocular barrier function is compromised. [30] Both in-vitro and in-vivo studies have demonstrated that AR inhibition or ablation prevents the activation of $\mathrm{PKC} / \mathrm{NF}-\kappa \mathrm{B}$ thereby attenuate cytotoxicity and tissue damage. [31] It has also been shown that AR inhibition in rodent endotoxin-induced uveitis model leads to attenuation of ocular inflammation as characterized by decreased protein extravasations and cellular infiltration into the anterior chamber [24]. These results 
demonstrated that $\mathrm{AR}$ inhibition leads to in-vivo suppression of NF- $\kappa \mathrm{B}$ that can attenuate inflammation in the eye. In HLEC, it has recently been shown that AR mediates the LPSinduced cytotoxicity via the activation of redox sensitive transcription factors NF- $\kappa B$ and AP-1, and inhibition of AR by pharmacological inhibitor or by silencing the AR expression by AR siRNA prevented the cytotoxicity caused by LPS. [32] These findings are significant as LPS induced ocular inflammation, such as endogenous endophthalmitis in which infection reaches the eye via circulation and infection-induced uveitis, are well known threats to vision in humans. [33,34] Inhibition of such inflammation by AR inhibitors provides a novel therapeutic approach for infection -induced ocular diseases. Further, a study by Kubo et al showed that over-expression AR in HLEC led to the increased oxidative stress and apoptosis, and inhibition of AR prevented the cells from oxidative stres. [35] In a recent study, it has been demonstrated that AR mediates LPS-induced cytotoxicity in non-pigmented ciliary epithelial cells and disturbs the aqueous humor dynamics by altering the expression of channel proteins such as Na-K-ATPase. [36] This study has greater implication in the infection-induced ocular inflammation as reduced flow of aqueous humor could result in severe vision impairment or vision loss. Besides, attraction of macrophages to the ocular tissues or activation of resident macrophages e.g. dendritic cells during inflammation cause severe damage to the ciliary body and retinal layers. [33-35] The role of AR in LPS-induced inflammation and macrophage activation is important because macrophages play an important role in the ocular inflammation such as uveitis. Macrophages infiltrate the vasculature and enter the aqueous humor in anterior segment releasing enormous amount of cytokines and chemokines that result in the pathological symptoms of uveitis such as flare, cell, edema, and vasodilation. [37] Therefore, it is significant in the way that AR inhibition provides a novel therapeutic target in ocular inflammatory diseases. Studies in the cellular models provide an evidence of an unanticipated role of AR in mediating acute inflammatory responses, and also inhibition of AR might be therapeutically useful in preventing ocular inflammation induced by oxidative stress especially in various pathological conditions.

\section{Basic principles in the treatment of endogenous}

\subsection{Endophthalmitis}

The therapy of infectious endophthalmitis remains a controversial issue because progression and suboptimal outcome occur despite bacteriologic cure of the intraocular infection. The irreversible tissue destruction during the inflammatory process may result largely from a secondary host inflammatory response. However, adjunctive treatment with immunosuppressive agents may interfere with the ability of the immune system to eliminate the microorganisms. Hence the option of adjunctive immunosuppression in the therapy of infectious endophthalmitis is still on debate. Endogenous endophthalmitis is treated by a combination of broad-spectrum antibiotics (vancomycin and ceftazidime or amikacin), which are administered intravitreally, subconjunctivally and topically, if appropriate in combination by systemic antibiotics (vancomycin and ceftazidime or amikacin). [1,2] If vision diminishes to mere light perception, performance of pars plana vitrectomy is indicated. [2-4] In mycotic 
endophthalmitis, antimycotics (amphotericin B) are administered intravitreally. [38,39] If findings are severe, a pars plana vitrectomy must also be carried out. [40,41] Antimycotics are applied topically to support treatment. [38] Systemic therapy with antibiotics or mycotics is obligatory. [42]

\subsection{Topical antimicrobial agents}

Fluoroquinolones are especially useful because they possess a broad antibacterial spectrum, bactericidal in action, are generally well tolerated, and have been less prone to development of bacterial resistance. [43]

Second-generation fluoroquinolones; Ciprofloxacin $0.3 \%$ and Ofloxacin $0.3 \%$ have been widely used in the treatment and prophylaxis of ocular infections. $[43,44]$ However, their invitro potencies have been decreasing steadily since their introduction. But ciprofloxacin remains the most effective fluoroquinolone against gram-negative bacteria. Minimal inhibitory concentration at $90 \%$ level (MIC90) for ciprofloxacin is lower in gram-negative bacteria. MIC90 for ofloxacin is higher against Haemophilus spp. and Moraxella spp. Ciprofloxacin is clinically the most potent fluoroquinolone for Pseudomonas spp. Ciprofloxacin is just as potent as gatifloxacin for the other gram-negative isolates.[44]Third-generation fluoroquinolones; Levofloxacin $0.5 \%$ produces higher ocular tissue penetration, thereby reducing the risk of selecting for decreased fluoroquinolone potency. A new third-generation formulation, levofloxacin $1.5 \%$, is recently introduced, demonstrating increased ocular penetration compared with gatifloxacin $0.3 \%$, but clinical equivalence to its second-generation parent, ofloxacin $0.3 \%$, in two randomized trials. [45]Fourth-generation fluoroquinolones; Fourth-generation agents have increased potency against gram-positive bacteria compared with levofloxacin, while maintaining similar potency against gram-negative bacteria. [46] Although levofloxacin $1.5 \%$ has demonstrated superior ocular penetration relative to gatifloxacin, the limited available data do not suggest this translates into superior clinical activity compared with moxifloxacin, which has significantly greater ocular penetration and better gram-positive potency than gatifloxacin. [46] Gatifloxacin $0.3 \%$ and moxifloxacin $0.5 \%$ have structural modifications that both reduce risk of resistance and improve potency against gram-positive bacteria. Fourth-generation agents have increased potency against gram-positive bacteria compared with levofloxacin, while maintaining similar potency against gram-negative bacteria. [47] From susceptibility profiles achieved with in vitro testing, the fourth-generation fluoroquinolones may offer some advantages over the currently available fluoroquinolones; however, a combination of the pharmacodynamics and pharmacokinetics of the drug, infection site, and the MIC90 is needed to predict the in vivo efficacy and best clinical applicability. [47] The fourth-generation fluoroquinolones are clinically more potent than the second generations for gram-positive bacteria. The MIC90 level is lower for moxifloxacin than that for gatifloxacin against Staphylococcus aureus, methicillin-susceptible coagulase-negative Staphylococcus (CoNS), and Streptococcus pneumoniae, whereas the levels are equal against Streptococcus viridans and the gatifloxacin MIC90 is lower in methicillin-resistant coagulase-negative CoNS [48] With in vitro tests, Staphylococcus aureus isolates that are resistant to ciprofloxacin and ofloxacin are clinicallymost susceptible to moxifloxacin. CoNS, that are resistant to ciproflox- 
acin and ofloxacin are clinically most susceptible to moxifloxacin and gatifloxacin. [48]Streptococcus viridans are more susceptible to moxifloxacin, gatifloxacin and levofloxacin than ciprofloxacin and ofloxacin. Streptococcus pneumoniae is least susceptible to ofloxacin compared with the other fluoroquinolones. [48] Susceptibilities are found equivalent for all other bacterial groups. In general, moxifloxacin is the most potent fluoroquinolone for grampositive bacteria, while ciprofloxacin, moxifloxacin, gatifloxacin, and levofloxacin demonstrate equivalent potencies to gram-negative bacteria. [45,47] None of the fluoroquinolones are effective against ciprofloxacin-resistant gram-negative bacteria. Overall, for gram-positive bacteria, median MIC90s of levofloxacin, moxifloxacin and gatifloxacin are below ciprofloxacin, the MIC90 of gatifloxacin and moxifloxacin is equal for gram-positive bacteria. Levofloxacin, gatifloxacin and moxifloxacin are clinically more effective against gram-positive bacteria, the latter two being equally effective. Ciprofloxacin remains the most effective fluoroquinolone against gram-negative bacteria. [45,48] Fourth-generation fluoroquinolone moxifloxacin, seems to have better penetration to the inflamed ocular tissues in rabbit. [49] Moxifloxacin has a spectrum of coverage that encompasses the most common organisms in endophthalmitis. [49] Because of their broad spectrum of coverage, low MIC90, good tolerability, and excellent oral bioavailability, fourth-generation fluoroquinolones are considered to represent a major advance for managing posterior segment infections. [47,49]

Delivery of moxifloxacin via a collagen shield is recommended when high concentrations of moxifloxacin are most needed to clear the aqueous of bacteria. [50] There are several advantages of this route of delivery that make it appealing over the frequent topical drop use in the immediate period. [50] Future studies are considered to define precisely the role of fourthgeneration fluoroquinolones and presoaked collagen shields in the prophylaxis or management of intraocular infections.

Orally administered gatifloxacin achieves therapeutic levels in the noninflamed human eye, and the activity spectrum appropriately encompass the bacterial species most frequently involved in the various causes of endophthalmitis. Because of its broad-spectrum coverage, low MIC90 levels for the organisms of concern, and good tolerability, gatifloxacin represents a major advance in the prophylaxis or treatment of bacterial endophthalmitis including Staphylococcus epidermidis, Staphylococcus aureus, Streptococcus pneumoniae, Streptococcus pyogenes, Propionibacterium acnes, Haemophilus influenzae, Escherichia coli, Bacillus cereus, Proteus mirabilis, and other organisms. [51] Besifloxacin, the latest advanced fluoroquinolone approved for treating bacterial conjunctivitis is the first fluoroquinolone developed specifically for topical ophthalmic use. [52] It has a C-8 chlorine substituent and is known as a chloro-fluoroquinolone. Besifloxacin possesses relatively balanced dual-targeting activity against bacterial topoisomerase IV and DNA gyrase (topoisomerse II), two essential enzymes involved in bacterial DNA replication, leading to increased potency and decreased likelihood of bacterial resistance developing to besifloxacin. [52] Microbiological data suggest a relatively high potency and rapid bactericidal activity for besifloxacin against common ocular pathogens, including bacteria resistant to other fluoroquinolones, especially resistant staphylococcal species. [52,53] Randomized, double-masked, controlled clinical studies demonstrated the clinical efficacy of besifloxacin ophthalmic suspension $0.6 \%$ administered three-times daily for 
5 days to be superior to the vehicle alone and similar to moxifloxacin ophthalmic solution $0.5 \%$ for bacterial conjunctivitis. [53] In addition, besifloxacin ophthalmic suspension $0.6 \%$ administered two-times daily for 3 days isclinically more effective than the vehicle alone for bacterial conjunctivitis. Besifloxacin has also been shown in preclinical animal studies to be potentially effective for the "off-label" treatment of infections following ocular surgery, prophylaxis of endophthalmitis, and the treatment of bacterial keratitis. Taken together, clinical and preclinical animal studies indicate that besifloxacin is an important new option for the treatment of ocular infections. [53]Both besifloxacin and moxifloxacin achieved aqueous humor concentrations equal to or slightly higher than their respective MIC90 for methicillin-resistant and methicillin-susceptible Staphylococcus aureus and Staphylococcus epidermidis; none of the fluoroquinolones achieved concentrations above their MIC90 for ciprofloxacin-resistant strains of Staphylococccus aureus and Staphylococcus epidermidis. [54] Based on the aqueous humor drug concentrations measured, it is unlikely that any of the fluoroquinolones tested would be therapeutically effective in the aqueous humor against the most frequently identified drug-resistant Staphylococcal isolates from cases of endophthalmitis. [54] As well as; none of the fluoroquinolones reduce the number of bacteria recovered from the vitreous humor. [54] Besifloxacin is as effective as moxifloxacin and gatifloxacin in a rabbit model for topical prophylaxis and treatment of pneumococcal endophthalmitis. [55] Besifloxacin acts as an antiinflammatory agent in corneal epithelial cells in vitro, by inhibiting the nuclear factor, NF- $\kappa \mathrm{B}$ and mitogen-activated protein kinase (MAPK) pathways. Besifloxacin also exhibits antiinflammatory efficacy in vivo. [56] The anti-inflammatory attribute may enhance its efficacy in the treatment of ocular infections with an inflammatory component and warrants further investigation. [56] The newer topical fluoroquinolones gemifloxacin and pazufloxacin are considered as effective as moxifloxacin and levofloxacin for topical prophylaxis and for the treatment of Staphylococcus aureus-induced endophthalmitis in the rabbit model. [57]

Early diagnosis and appropriate treatment with intravitreous antibiotics are the most important factors for the successful management of endophthalmitis. [58,59] The intraocular concentration of antibiotics after intravitreous injection is far greater than that achieved by topical modalities. Drug combinations are necessary to cover the full range of bacteria causing endophthalmitis. [58,59] Vancomycin $(1 \mathrm{mg} / 0.1 \mathrm{ml})$ is considered the drug of choice for grampositive organisms. Controversy remains concerning the best choice against gram-negative bacteria. Aminoglycosides (amikacin, $0.4 \mathrm{mg} / 0.1 \mathrm{ml}$ ) have traditionally been recommended for gram-negative coverage. However, because of their possible role in macular toxicity, recent trends have shifted to using ceftazidime $(2.25 \mathrm{mg} / 0.1 \mathrm{ml})$ in combination with vancomycin. [59] Intracameral or intravitreal cefuroxime at a dose of $1 \mathrm{mg}$ is considered effective in the treatment of endophthalmitis. [60] Electroretinographic (ERG) and histologic findings indicated that a dose of $1 \mathrm{mg}$ cefuroxime, administered intravitreally, is not toxic to the rabbit retina. [60] A dose of $10 \mathrm{mg}$, injected intravitreally, induce transient physiological effects, and is toxic to the rabbit retina, as was evident by the permanent reduction in the ERG responses and by the structural damage to the retina with signs of glial activation. [60] The long-term outcomes of early intravitreal treatment of endogenous bacterial endophthalmitis, defined as intravitreal and systemic antibiotics administered within $24 \mathrm{~h}$ of diagnosis, with conservative use of pars plana vitrectomy is considered to provide a relatively favourable visual prognosis. 
[61] The longer the time between onset of ocular symptoms and intravitreal antibiotic injection is correlated with worse visual outcomes, and it is also associated with increased mortality. [61] Mortality is also associated with methicillin-resistant Staphylococcus aureus infection. [61] Methicillin-resistant Sthapylococcus aureus isolates are reported sensitive to vancomycin, and $68 \%$ were sensitive to the fourth-generation fluoroquinolones. [62] No significant differences are reported in visual acuity outcomes of endophthalmitis caused by methicillin-sensitive Sthaphylococcus aureus versus methicillin-resistant Staphylococcus aureus treated early intravitreal vancomycin and either ceftazidime or amikacin.[62] Adjunt use of intravitreal dexamethasone in endogenous endophthalmitis is recommended. [63] No adverse events is attributed to the dexamethasone, and it appears safe and may be of benefit in endogenous endophthalmitis. [63] The advantage of corticotherapy combined with specific anti-infective treatment has been proven for certain bacterial and fungal infections. Corticosteroids, even in short-term treatments, is recommended to be prescribed in combination with antibiotics in the course of infections related to their ability to limit the deleterious effects caused by the activation of the immune system at the time of certain infections.[64] Such as; Bacillus cereus causes the most virulent and refractory form of endophthalmitis. Eyes treated with intravitreal vancomycin in conjunction with dexamethasone injection at 7 days and 14 days show significantly less inflammation over iris and vitreous than the eyes treated with intravitreal vancomycin injection alone.[65] Additionally, at 14 days, the histopathological changes of eyes treated with vancomycin with dexamethasone show less conjunctival inflammation, mild iridocyclitis, less vitreous cells, and less choroidal vasculitis and retinitis compared to the vancomycin treatment alone. [65] Intravitreal injection of vancomycin is considered to improve the therapeutic outcome of Bacillus cereus endophthalmitis. However, the addition of dexamethasone to antibiotic treatment is reported to provide a therapeutic benefit over antibiotic alone. [65]

The fluocinolone acetonide intravitreal implants a sustained drug delivery implant has been used for patients with posterior uveitis who do not respond to or are intolerant to conventional treatment. [66] It effectively controls the intraocular inflammation. Visual acuity generally improves, uveitis recurrences, and the need for immunosuppression decreases. However, the most common side effect is increased intraocular pressure, and cataract development is also reported. [66,67] The newly approved dexamethasone implant, Ozurdex, is currently considered in the treatment of noninfectious intermediate and posterior uveitis given its efficacy, safety, and ease of use in the outpatient setting. [68]

Triamcinolone acetonide (TA) is an effective steroid drug for various retinal and choroidal diseases when delivered intravitreally. [69] It may imply an off-label use and it may be associated with ocular adverse events. Intravitreal TA is not associated with significant systemic safety risks. [69] Difluprednate $0.05 \%$ ophthalmic emulsion is a potent new topical corticosteroid that exhibits enhanced penetration, better bioavailability, rapid local metabolism and strong efficacy, with a low incidence of adverse effects. In June 2008, difluprednate ophthalmic emulsion $0.05 \%$ gained FDA approval in the U.S. for the treatment of postoperative ocular inflammation and pain. Recently, a multicenter, randomized clinical trial showed difluprednate to be noninferior to prednisolone acetate $1 \%$ dosed twice as often, the current 
standard of care for the acute management of endogenous uveitis in the U.S. Furthermore, difluprednate proved to have a comparable safety profile. [70]

Intravitreous amphotericin B injection associated with, pars plana vitrectomy, systemic amphotericin B therapy, and oral anti-fungal therapy are indicated in the treatment of endogenous fungal endophthalmitis. [71,72] The most common cause of culture-proven endogenous fungal endophthalmitis is Candida species. [71] Endogenous Aspergillus endophthalmitis usually has an acute onset of intraocular inflammation and often has a characteristic chorioretinal lesion located in the macula. (Fig 6] [72] Although treatment with pars plana vitrectomy and intravitreous amphotericin B is capable of eliminating the ocular infection, the visual outcome generally is poor, especially when there is direct macular involvement. [72] The overall visual outcomes are reported more favorable for Candida cases than they are for Aspergillus cases. [71] Infection site, illness severity, neutropenia, hemodynamic status, organ failure and concomitant drug treatments are host-related factors that influence the choice of systemic antifungal treatment. [73] In general, echinocandins are currently favored for empiric treatment of candidemia, especially in critically ill patients or those with previous azole exposure. Essentially, patients who have been previously exposed to azoles have a higher probability of being infected by azole-resistant or non-albicans strains. [73] Pharmacokinetic properties and side effects suggest that polyenes should be avoided in patients with renal failure, and that echinocandins and azoles should be avoided in patients with severe hepatic dysfunction. [73] Intravitreal corticosteroid therapy which is also indicated in conjunction with anti-fungals with and without vitrectomy, reduces the intraocular inflammatory process and secondary complications associated with fungalendophthalmitis. [74]
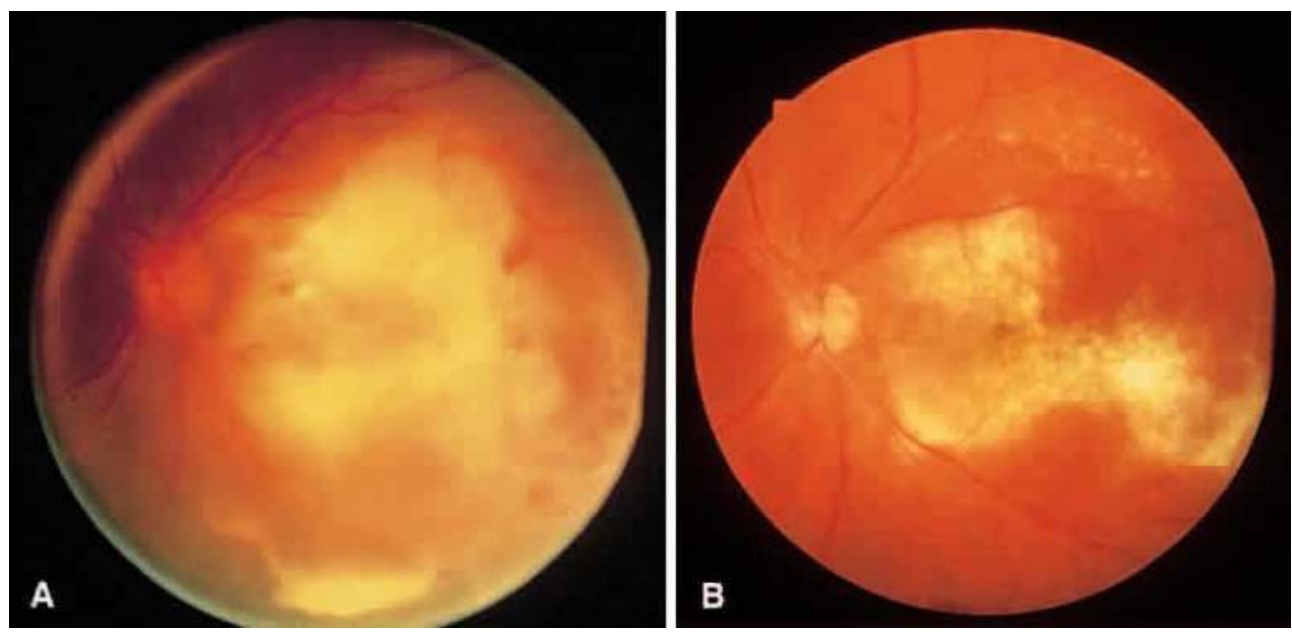

Figure 6. A. Aspergillus chorioretinal infiltrate in macula of patient with a history of intravenous drug abuse. B. After treatment with vitrectomy, intravitreal amphotericin B injection, and systemic amphotericin $B$, the infection resolved and a macular scar remains. (Weishaar PD, Flynn HW Jr, Murray TG et al: Endogenous Aspergillus endophthalmitis: Clinical features and treatment outcomes. Ophthalmology 105:57, 1998.) 
Tumor Necrosis Factor-Alpha (TNF $\alpha)$ is a potent mediator of acute inflammatory reactions via activation of proinflammatory signaling cascades. [75] TNF $\alpha$ is a cytokine secreted by macrophages and neutrophils, and is important in upregulating cell adhesion expression on vascular endothelial cells. [75] TNF $\alpha$ also stimulates mononuclear phagocytes to produce cytokines, such as interlekin (IL)-1, IL-6 and itself. [75] In an experimental rat model of Staphylococcus aureus endophthalmitis, TNF $\alpha$ and IL-1 $\beta$ were detected in the vitreous within $6 \mathrm{~h}$ of intravitreal inoculation. [76] It has been shown that the upregulation of proinflammatory cytokines may have contributed to the breakdown of the blood-retina barrier, and the recruitment of neutrophils into the eye. [76] Upregulation of $\mathrm{TNF} \alpha$, IL-1 $\beta$, and interferon gamma (IFN $\gamma$ ) have also been shown in experimental Staphylococcus epidermidis endophthalmitis.[77] Injection of TNF $\alpha$ into the vitreous of rabbits and rats induced increased vascular permeability and cellular infiltration. [78,79] Studies have also demonstrated upregulation of $\mathrm{TNF} \alpha$ and other proinflammatory cytokines in experimental autoimmune uveoretinitis. [80] No studies have quantified cytokines or chemokines in the human eye during endophthalmitis, but based on experimental studies, it is reasonable to hypothesize that proinflammatory cytokines are key mediators of acute inflammation during endophthalmitis. The primary function of innate immunity is to detect invading pathogens and clear them as quickly as possible. [80] During an acute intraocular infection, a primary and essential component of this response is neutrophil influx. Cellular infiltration in human endophthalmitis cases has been described as vitritis, the presence of a hypopyon, and corneal ring abscess formation. Experimental models have identified polymorphonuclear leukocytes (PMN) as the primary infiltrating cell type during bacterial endophthalmitis.[81-84]The recruitment and activation of neutrophils within an infected eye is a biological dilemma. PMN infiltration is necessary for bacterial clearance, but the generation of toxic reactive oxygen intermediates and other inflammatory mediators by PMN may result in bystander damage to delicate tissues of the retina.[81,82] Robust inflammation is a hallmark of endophthalmitis caused by B. cereus and other types of virulent bacteria. In experimental B. cereus endophthalmitis, inflammatory cells were observed in the posterior chamber in close proximity to the optic nerve head as early as 4 $\mathrm{h}$ postinfection. [82] Further analysis confirms that the primary infiltrating cells are the PMNs. The numbers of $\mathrm{CD} 18^{+} / \mathrm{Gr}-1^{+} \mathrm{PMN}$ were minimal at 4 and $6 \mathrm{~h}$ postinfection, but increased significantly thereafter. The influx of $\mathrm{CD} 18^{+} / \mathrm{Gr}-1^{+} \mathrm{PMN}$ into the posterior segment occurred simultaneously with the increase of TNF $\alpha$ in the eye at approximately 4-6 h postinfection.[82] Despite their potential importance, the roles of TNF $\alpha$ and several other cytokines in endophthalmitis remain unexplored. Regulation of inflammation is the key to removing the pathogen without harming the eye, but bystander damage from infiltrating cells might occur. For Staphylococcus aureus endophthalmitis, depletion of neutrophils early in the inflammatory response reduces the severity of host inflammation, but severely hamperes bacterial clearance, resulting in a more severe infection. [81] Pathogen recognition and a well-regulated inflammatory response to infection are essential in clearing invading organisms with minimal damage to surrounding tissue. A tightly controlled response is even more critical in the eye, where non-regenerative cells and tissues responsible for vision reside. Experimental models of bacterial endophthalmitis have 
demonstrated that once a pathogen is introduced into the posterior segment, an acute response occurs, including synthesis of proinflammatory cytokines and influx of PMN into the eye.[83,84] In the case of virulent pathogens such as Staphylococcusaureus or Bacillus cereus, low numbers of bacteria can be cleared effectively by an adequate inflammatory response.[83] Once an inoculum threshold is passed, bacterial growth and toxin production overwhelm the inflammatory response. In an exhaustive attempt to clear the infection, PMN fill the posterior and anterior segments. Because the absence of TNF $\alpha$ has beendemonstrated to dampen the initial inflammatory response during Bacillus cereus endophthalmitis, several studies have also analyzed whether therapy targeting TNF $\alpha$ would effectively attenuate inflammation. The anti-inflammatory potential of anti-TNF $\alpha$ has been shown after injected immediately prior to Bacillus cereus infection.[82] Infliximab, anti$\mathrm{TNF} \alpha$ antibody has attenuated intraocular inflammation in experimental models of choroidal neovascularization, endotoxin-induced uveitis, and in human uveitis patients. [85-88] Infliximab was recently shown to be non-toxic at levels up to $1.7 \mathrm{mg}$ in rabbit eyes. [89]

These findings suggest the potential for attenuation of inflammation during endophthalmitis by targeting TNF $\alpha$ and perhaps other cytokines, but this sort of therapy would likely be best suited for the initial stages of infection.[90] Continuing studies will determine the therapeutic potential of cytokine targeting in conjunction with early antibiotic treatment in reducing inflammation during endogenous endophthalmitis.

\section{Future directions}

Since AR has been advocated as an important therapeutic target to treat oxidative stressinduced inflammatory disorders including ocular inflammation, detailed studies of the molecular events and clear understanding of AR's involvement in the pathogenesis of inflammation is required. Understanding this role of AR should provide pharmacological tools for eventual therapeutic interventions to control cell proliferation, apoptosis, tissue repair, and prevention of the cytotoxicity of cytokines and chemokines which are elevated during ocular inflammation. More importantly, these studies will provide a mechanistic link between AR with ocular inflammation. Studies using various animal models are required to clearly understand the mechanism of AR's involvement in the inflammation and related pathologies which in turn will help in the design and synthesis of more specific inhibitors. Common limitations for some of the earlier AR inhibitors (ARI) such as sorbinil and tolrestat include critical hepatic and renal toxicity for long-term use. [91] Newer AR inhibitors such as zopolrestat, raneristat and fidarestat are now being tested for their ability to prevent the progression of diabetic neuropathy. Since these drugs have already passed in the Food and Drug Administration (FDA)'s phase I and II clinical trials and have been found to be safe without any major irreversible side effects, and it is expected that ARI such as fidarestat could be developed as novel therapy for preventing ocular inflammation especially uveitis in a relatively shorter time. [92-94] 


\section{Author details}

Ozlem Sahin

Dunya Eye Hospital Ltd. Ankara, Turkey

\section{References}

[1] Mamalis N. Endophthalmitis. J Cataract Refract Surg. 2002;28(5):729-730.

[2] Essman TF, Flynn HW, Jr, Smiddy WE, et al. Treatment outcomes in a 10-year study of endogenous fungal endophthalmitis. Ophthalmic Surg Lasers. 1997;28(3):185-194.

[3] Jackson TL, Eykyn SJ, Graham EM, Stanford MR. Endogenous bacterial endophthalmitis: 17-year prospective series and review of 267 reported cases. Surg Ophthalmol. 2003;48(4):403-423.

[4] Okada AA, Johnson RP, Liles WC, D'Amico DJ, Baker AS. Endogenous bacterial endophthalmitis. Report of a ten-year retrospective study. Ophthalmology. 1994;101(5): 832-838.

[5] Rao NA, Hidayat AA. Endogenous mycotic endophthalmitis: Variations in clinical and histopathologic changes in candidiasis compared with aspergillosis. Am J Ophthalmol. 2001;132(2):244-251.

[6] Tanaka M, Kobayashi Y, Takebayashi H, Kiyokawa M, Qiu H. Analysis of predisposing clinical and laboratory findings for the development of endogenous fungal endophthalmitis. A retrospective 12-year study of 79 eyes of 46 patients. Retina. 2001;21(3):203-209.

[7] Kernt M, Kampik A. Endophthalmitis: pathogenesis, clinical presentation, management and prspectives. Clin Ophthalmol 2010;4:121-35.

[8] Dinani A, Ktaich N, Urban C, Rubin D.Levofloxacin-resistant-Streptococcus mitis endophthalmitis: a unique presentation of bacterial endocarditis.J Med Microbiol 2009;58:1385-7.

[9] Gery I, Streilein JW. Curr Opin Immunol. 1994;6:938-945.

[10] Forrester JV, McMenamin PG. Chem Immunol. 1999;73:159-185.

[11] Cho H, Wolf KJ, Wolf EJ. Clin Ophthalmol. 2009;3:199-210.

[12] Wagoner MD. Surv Ophthalmol. 1997;41:275-313.

[13] Cho H, Wolf KJ, Wolf EJ. Clin Ophthalmol. 2009;3:199-210.

[14] Mittag T. Exp Eye Res. 1984;39:759-769. 
[15] Rao NA, Romero JL, Fernandez MA, Sevanian A, Marak GE., Jr Surv Ophthalmol. 1987;32:209-213.

[16] Rao NA. Trans Am Ophthalmol Soc. 1990;88:797-850.

[17] Ahn KS, Sethi G, Aggarwal BB. Curr Mol Med. 2007;7:619-637.

[18] Srivastava SK, Ramana KV. Exp Eye Res. 2009;88:2-3.

[19] Tak PP, Firestein GS. J Clin Invest. 2001;107:7-11

[20] Li Q, Verma IM. Nat Rev Immunol. 2002;2:725-734.

[21] Makarov SS. Mol Med Today. 2000;6:441-448.

[22] Uwe S. Biochem Pharmacol. 2008;75:1567-1579.

[23] Sarkar FH, Li Y, Wang Z, Kong D. Int Rev Immunol. 2008;27:293-319.

[24] Yadav UC, Srivastava SK, Ramana KV. Invest Ophthalmol Vis Sci. 2007;48:46344642.

[25] Pladzyk A, Reddy ABM, Yadav UCS, Tammali R, Ramana KV, Srivastava SK. Invest Ophthalmol Vis Sci. 2006;47:5395-5403.

[26] Ramana KV, Fadl AA, Tammali R, Reddy AB, Chopra AK, Srivastava SK. J Biol Chem. 2006;28:33019-33029.

[27] Pladzyk A, Reddy ABM, Yadav UCS, Tammali R, Ramana KV, Srivastava SK. Invest Ophthalmol Vis Sci. 2006;47:5395-5403.

[28] Akagi Y, Yajima Y, Kador PF, Kuwabara T, Kinoshita JH. Diabetes. 1984;33:562-566.

[29] Kinoshita JH, Kador P, Catiles M. JAMA. 1981;246:257-261.

[30] Streilein JW, Ohta K, Mo JS, Taylor AW. DNA Cell Biol. 2002;21:453-459.

[31] Yadav UC, Ighani-Hosseinabad F, van Kuijk FJ, Srivastava SK, Ramana KV. Invest Ophthalmol Vis Sci. 2009;50:752-759.

[32] Pladzyk A, Ramana KV, Ansari NH, Srivastava SK. Exp Eye Res. 2006;83:408-416.

[33] Yang P, de Vos AF, Kijlstra A. Br J Ophthalmol. 1997;81:396-401.

[34] McMenamin PG, Crewe J. Invest Ophthalmol Vis Sci. 1995;36:1949-1959.

[35] Kubo E, Urakami T, Fatma N, Akagi Y, Singh DP. Biochem Biophys Res Commun. 2004;314:1050-1056.

[36] Skeie JM, Mullins RF. Eye. 2009;23:747-755.

[37] Ohta K, Nakayama K, Kurokawa T, Kikuchi T, Yoshimura N. Invest Ophthalmol Vis Sci. 2002;43:744-750. 
[38] De Rosa FG, Garazzino S, Pasero D, Di Perri G, Ranieri VM. Invasive candidiasis and candidemia: new guidelines. Minerva Anestesiol 2009;75:453-8.

[39] Weishaar PD, Flynn HW Jr, Murray TG, Davis JL, Barr JG, Mein CE, McLean WC Jr, Killian JH. Endogenous Aspergillus endophthalmitis. Clinical features and treatment outcomes. Ophthalmology 1988;105:57-65.

[40] Yonekawa Y, Chan RV, Reddy AK, Pieroni CG, Lee TC, Lee S. Early intravitreal treatment of endogenous bacterial endophthalmitis. Clin Experiment Ophthalmol 2011;39:771-8.

[41] Kain HL. Basic principles in the treatment of endophthalmitis. Klin Monbl Augenheilkd 1997;210:274-88.

[42] Meier P, Wiedemann P. Endophthalmitis: clinical Picture, therapy and prevention. Klin Monabl Augenheilkd 1997;210:175-91.

[43] Scoper SV. Review of third-and fourth-genertion fluoroquinolones in ophthal-mology:in-vitro and in-vivo efficay. Adv Ther 2008;25:979-94.

[44] Oliveria AD, D'Azevedo PA, Francisco W. In vitro activity of fluoroquinolones against ocular bacterial isolates in Sao Paulo, Brazil. Cornea 2007;26:194-8.

[45] Duggirala A, Joseph J, Sharma S, Nutheti R, Garg P, Das T. Activity of newer fluoroquinolones against gram-positive and gram-negative bascteria isolated from ocular infections: in vitro comparison. Indian J Ophthalmol 2007;55:15-9.

[46] Jackson TL, Eykyn SJ, Graham EM, Stanford MR. Endogenous bacterial endophthalmitis : a 17-year prospective series and review of 267 reported cases. Surv Ophthalmol 2003;48:403-23.

[47] Mather R, Karenchak LM, Romanowski EG, Kowalski RP. Fourth generation fluoroquinolones: new weapons in the Arsenal of ophthalmic antibiotics. Am J ophthalmol 2002;133:463-6.

[48] Oliveria AD, Höfling-Lima AL, Belfort R Jr, Gayoso Mde F, Francisco W. Fluoroquinolone susceptibilities to methicillin-resistant and susceptible coagulkase-negative Staphylococcus isolated from eye infection. Arq Bras Oftalmol 2007;70:286-9.

[49] Yagcı R, Oflu Y, Dinçel A, Kaya E, Yagcı S, Bayar B, Duman S, Bozkurt A. Penetration of second-third-and fourth generation topical fluoroquinolone into aqueous and vitreous humour in a rabbit endophthalmitis model. Eye 2007;21:990-4.

[50] Hariprasad SM, Shah GK, Chi J, Prince RA. Determination of aqueous and vitreous concentration of moxifloxacin $0.5 \%$ after delivery via a dissolvable corneal collagen shield device. J Cataract Refract Surg 2005;31:2142-6.

[51] Hariprasad SM, Mieler WF, Holz ER. Vitreous and aqueous penetration of orally administered gatifloxacin in humans. Arch Ophthalmol 2003;121:345-50. 
[52] O'Brien TP. Besifloxacin ophthalmic suspension $0.6 \%$ : a novel topical fluoroquinolone for bacterial conjunctivitis. Adv Ther 2012; Epub ahead of print.

[53] Malhotra R, Gira J, Berdy GJ, Brusatti R. Safety of besifloxacin ophtahlmic suspension $0.6 \%$ as a prophylactic antibiotic following routine catarct surgery: result of a prospective, paralel-group, investigator-mascked study. Clin Ophtahlmol 2012;6:855-63.

[54] Donnenfeld ED, Comstock TL, Proksch JW. Human aqeous humor concentrations of besifloxacin, moxifloxacin, and gatifloxacin after topical ocular application. J Cataract Refract Surg 2011;37:1082-9.

[55] Norcross EW, Sanders ME, Moore Q 3rd, Sanfilippo CM, Hesje CK, Shafiee A, Marquart ME. Comparative efficacy of besifloxacin and other fluoroquinolones in a prophylaxis model of penicilin-resistant Streptococcus pneumoniae rabbit endophtahlmitis. Pharmacol Ther 201;26:237-43.

[56] Zhang JZ, Cavet ME, Ward KW. Anti-inflammatory effects of besiflocaxin, a novel fluoroquinolone, in primary human corneal epithelial cells. Curr Eye Res 2008;33:923-32.

[57] Wu X, Chen H, Jiang H, Xu Y, Liu T, Xu L. Prophylactic effect of topical fluoroquinolones in a rabbit model of Stapylococcus aureus endophthalmitis. J Ocul Pharmacol Ther 2012;28:186-93.

[58] Cornut PL, Chiquet C. Intravitreal injection of antibiotics in endophthalmitis. J Fr Ophthalmol 2008;31:815-23.

[59] Mehta S, Armstrong BK, Kim SJ, Toma H, West JN, Yin H, Lu P, Wayman LL, Recchia FM, Sternberg P Jr. Long-term potency, sterility, and stability of vancomycin, cftazidime, and moxifloxacin for traetment of bacterial endophthalmitis. Retina 2011;31:316-22.

[60] Shahar J, Zemel E, Perlman I, Loewenstein A. Physioloical and toxicological effects of cefuroxime on the albino rabbit retina. Invest Ophthalmol Vis Sci 2012;21:906-14.

[61] Yonekawa Y, Chan RV, Reddy AK, Pieroni CG, Lee TC, Lee S. Early intravitreal treatment of endogenous bacterial endophtahlmitis. Clin Experiment Ophthalmol 2011;39:771-8.

[62] Miller DM, Vedula AS, Flynn HW jr, Miller D, Scott WE, Murray TG, Venkatraman AS. Endophthalmitis caused by staphylococcus epidermidis: in vitro antibiotic susceptibilities and clinical outcomes. Ophthalmic Surg Lasers Imaging 2007;38:446-51.

[63] Albertcht E, Richards JC, Pollock T, Cook C, Myers L. Adjunctive use of intravitreal dexamethasone in presumed bacterial endophthalmitis: a randomised trial. Br J Ophthalmol 2011;95:385-8. 
[64] Aslangul E, Le Jeunne C. Role of corticosteroids in infectious disease. Presse Med 2012;41:400-5.

[65] Liu F, Kwok AK, Cheung BM. The efficacy of intravitreal vancomycin and dexamethasone in the treatment of experimental bacillus cereus endophthalmitis. Curr Eye Res 2008;33:761-8.

[66] Jaffe GJ, McCallum RM, Branchaud B, Skalak C, Butuner Z, Ashton P. Long-term follow-up results of a pilot trial of a flucinolone acetonide implant to treat posterior uveitis. Ophthalmology 2005;112:1192-8.

[67] Chieh JJ, Crlson AN, Jaffe GJ. Combined flucinolone acetonide intraocular delivery system insertion, phacoemulsification and intraocular lens implantation for severe uveitis. Am J Ophthalmol 2008;146:589-94.

[68] Sarajya NV, Goldstein DA. DExamethasone for ocular inflammation. Expert Opin Pharmacother 2011;12:1127-31.

[69] Veritti D, Di Giulio A, Sarao V, Lanzetta P. Drug safety evaluation of intravitreal triamcinolone acetonide. Exp Opin Drug Saf 2012;11:331-40.

[70] Mulki L, Foster CS. Difluprednate for inflammatory eye disorders. Drugs Today (Barc) 2011;47:327-33.

[71] Essman TF, Flynn HW Jr, Smiddy WE, Brod RD, Murray TG, Davis JL, Rubsamen PE. Treatment outcomes in a 10-year study of endogenous fungal endophthalmitis. Ophthalmic Surg Lasers 1997;28:185-94.

[72] Weishaar PD, Flynn HW Jr, Murray TG, Davis JL, Barr CC, Gross JG, Mein CE, McLean WC Jr, Killian JH. Endogenous aspergillus endophthalmitis. Clinical features and treatment outcomes. Ophthalmology 1988;105:57-65.

[73] De Rosa FG, Garazzino S, pasero D, Di peri G, Ranieri VM. Invasive candidiasis and candidemia: new guidelines. Minerva Anestesiol 2009;75:453-8.

[74] Schulman JA, Peyman GA. Intravitreal corticosteroids as an adjunct in the traetment of bacterial and fungal endophthalmitis. A review. Retina 1992;12:336-40.

[75] Bazzoni F, Beutler B. The tumor necrosis factor ligand and receptor families. N Engl J Med. 1996;334:1717-25.

[76] Giese MJ, Sumner HL, Berliner JA, Mondino BJ. Cytokine expression in a rat model of Staphylococcus aureus endophthalmitis. Invest Ophthalmol Vis Sci. 1998;39:278590.

[77] Petropoulos IK, Vantzou CV, Lamari FN, Karamanos NK, Anastassiou ED, Pharmakakis NM. Expression of TNF-alpha, IL-1beta, and IFN-gamma in Staphylococcus epidermidis slime-positive experimental endophthalmitis is closely related to clinical inflammatory scores. Graefes Arch Clin Exp Ophthalmol. 2006;244:1322-28. 
[78] Luna JD, Chan CC, Derevjanik NL, Mahlow J, Chiu C, Peng B, Tobe T, Campochiaro PA, Vinores SA. Blood-retinal barrier (BRB) breakdown in experimental autoimmune uveoretinitis: comparison with vascular endothelial growth factor, tumor necrosis factor alpha, and interleukin-1beta-mediated breakdown. J Neurosci Res. 1997;49:268-80.

[79] De Vos AF, Van Haren MA, Verhagen C, Hoekzema R, Kijlstra A. Tumour necrosis factor-induced uveitis in the Lewis rat is associated with intraocular interleukin 6 production. Exp Eye Res. 1995;60:199-207.

[80] Dick AD, Forrester JV, Liversidge J, Cope AP. The role of tumour necrosis factor (TNF-alpha) in experimental autoimmune uveoretinitis (EAU) Prog Retin Eye Res. 2004;23:617-37.

[81] Giese MJ, Rayner SA, Fardin B, Sumner HL, Rozengurt N, Mondino BJ, Gordon LK. Mitigation of neutrophil infiltration in a rat model of early Staphylococcus aureus endophthalmitis. Invest Ophthalmol Vis Sci. 2003;44:3077-82.

[82] Ramadan RT, Ramirez R, Novosad BD, Callegan MC. Acute inflammation and loss of retinal architecture and function during experimental Bacillus endophthalmitis. Curr Eye Res. 2006;31:955-65.

[83] Giese MJ, Sumner HL, Berliner JA, Mondino BJ. Cytokine expression in a rat model of Staphylococcus aureus endophthalmitis. Invest Ophthalmol Vis Sci. 1998;39:278590.

[84] Ravindranath RM, Hasan SA, Mondino BJ. Immunopathologic features of Staphylococcus epidermidis-induced endophthalmitis in the rat. Curr Eye Res. 1997;16:103643.

[85] Olson JL, Courtney RJ, Mandava N. Intravitreal infliximab and choroidal neovascularization in an animal model. Arch Ophthalmol. 2007;125:1221-24.

[86] Shi X, Semkova I, Müther PS, Dell S, Kociok N, Joussen AM. Inhibition of TNF-alpha reduces laser-induced choroidal neovascularization. Exp Eye Res. 2006;83:1325-34.

[87] Diaz-Llopis M, García-Delpech S, Salom D, Udaondo P, Bosch-Morell F, Quijada A, Romero FJ, Amselem L. High-dose infliximab prophylaxis in endotoxin-induced uveitis. J Ocul Pharmacol Ther. 2007;23:343-50.

[88] Gallagher M, Quinones K, Cervantes-Castañeda RA, Yilmaz T, Foster CS. Biological response modifier therapy for refractory childhood uveitis. $\mathrm{Br} \mathrm{J}$ Ophthalmol. 2007;91:1341-44.

[89] Giansanti F, Ramazzotti M, Vannozzi L, Rapizzi E, Fiore T, Iaccheri B, Degl' Innocenti D, Moncini D, Menchini U. A pilot study on ocular safety of intravitreal infliximab in a rabbit model. Invest Ophthalmol Vis Sci. 2008;49:1151-56. 
[90] Wiskur BW, Robinson M, Farrand A, Novosad B, Callegan MC. Improved therapeutic regimens for Bacillus endophthalmitis. Invest Ophthalmol Vis Sci. 2008;49:1480 87.

[91] Tsai SC, Burnakis TG. Aldose reductase inhibitors: an update. Ann Pharmacother 1993;27:751-4.

[92] Yadav UC, Shoeb M, Srivastava SK, Ramana KV. Aldose reductase deficiency protects from autoimmune- and endotoxin-induced uveitis in mice. Invest Ophthalmol Vis Sci 2011; 52:8076-85.

[93] Yadav UC, Shoeb M, Srivastava SK, Ramana KV. Amelioration of experimental autoimmune uveo-retinitis by aldose reductase inhibition in Lewis rats.Invest Ophthalmol Vis Sci 52:8033-41.

[94] Srivastava SK, Yadav UC, Reddy AB, Saxena A, Tammali R, Shoeb M, Ansari NH, Bhatnagar A, Petrash MJ, Srivastava S, Ramana KV. Aldose reductase inhibition suppresses oxidative stress-induced inflammatory disorders. Chem Biol Interact 2011;191:330-8. 